\title{
Consumer Safety Officer
}

National Cancer Institute

\section{Source}

National Cancer Institute. Consumer Safety Officer. NCI Thesaurus. Code C142462.

An official of the Food and Drug Administration who coordinates the review process of sponsor applications. 